\title{
The Impact of Self-Protection and Self- Insurance on Individual Response to Risk
}

Jason F. Shogren

Working Paper 90-WP 53

March 1990 


\begin{abstract}
We develop four experimental markets to examine how individuals respond to risk: self-protection and self-insurance in both private and collective auctions. First, we find evidence that the mechanism used to reduce risk is important. Results indicate that the upper and lower bounds on value were elicited by the private self-protection and the collective self-insurance markets. Second, the robustness of these results declined with Iow probability lotteries. We find further evidence that individuals overestimate the impact of low probability events. overestimation decreased, however, with repeated market exposure. Third, the four markets induced rapid value formation. Usually only one or two additional market trials were necessary before an individual's perception and valuation of reduced risk stabilized.
\end{abstract}




\section{Introduction}

Two elements define risk: probability and severity. Ehrlich and Becker (1972) recognized that risk can be reduced by decreasing either element, privately or collectively. They define decreased probability as self-protection; decreased severity as self-insurance. Recent extensions of self-protection and self-insurance models have illustrated their wide applicability and importance to the theory of individual choice under risk [see for example Hiebert (1983), Centner and Wetzstein (1987), Shogren and Crocker (1989a)].

Although it is now generally recognized that self-protection and self-insurance exist, minimal attention has been given to systematically evaluating their comparative impact on individual response to risk. Given Tversky and Kahneman's (1981) work on choice under alternative decision frames, one might suspect that how a risk is reduced may be as important as what risk is reduced. The purpose of this paper is to examine how individuals respond to risk that is reduced either through private or collective self-protection or self-insurance. We construct an experimental design that incorporates self-protection and selfinsurance into four markets with alternative risk reduction mechanisms. For each market, the experiment elicited individual valuations of four risks in both hypothetical and nonhypothetical lotteries repeated over ten market trials.

The experimental design captures three issues basic to decision making under risk. First, we examine whether the risk reduction mechanism matters to valuation. Individuals confronted 
with risk have an assortment of ex ante reduction mechanisms to decrease the probability or severity of an ex post monetary or nonmonetary loss. For example, an individual exposed to potentially contaminated drinking water can privately reduce the probability of illness by purchasing a water filter, or he can contribute to a collective scheme to filter the water in a centralized location. Alternatively, the individual can privately or collectively reduce the severity of the hazard through preventive meaical care, nutrition, or exercise.

Although psychologists have discovered that alternative means of framing equivalent problems lead to systematic differences in choice, economists have previously not addressed whether alternative risk reduction mechanisms affect valuation. our results suggest the mechanism matters. Reducing risk by altering the probability or severity of an undesirable event through a private mechanism induced significantly different value estimates. Private self-protection was preferred to selfinsurance. In addition, private mechanisms were valued significantly greater than the collective mechanisms for both self-protection and self-insurance. Generally, the upper bound of value is generated by the private provision of selfprotection. The lower bound of value is obtained by the collective provision of self-insurance. Consequently, future attempts to value risk should consider all alternative reduction mechanisms to capture a more comprehensive view of economic value. 
The second basic issue explored is how individuals value reductions over a range of risks. Both psychologists and economists have uncovered evidence that individuals are oversensitive to changes in the probabilities of low probability events [see Machina (1983) for overview]. If individuals overestimate the value of reducing risk associated with low probability events, then more resources will be devoted to risk reduction than is economically efficient. To determine whether the subjects over estimate low probability events, a range of risks is examined. Four binary lotteries are constructed given a fixed loss and gain with probability of a loss being 1\%, $10 \%$, 20\%, and 40\%. To compare across lotteries, we examine the individual's risk premium payment. We also consider how the risk premiums respond to the alternative reduction mechanisms over repeated market trials.

We find further evidence that individuals overestimate the impacts of low probability events as evidenced by relatively large initial risk premium payments. The initial valuations do not conform to the expected utility requirement of linearity in probabilities as reflected by individual willingness to pay an excessive risk premium for the 18 lottery period. Although this is not encouraging since many risks are less than $1 \%$ per year or lifetime, risk premiums decrease significantly with repeated market interactions, especially in the self-insurance risk reduction markets. 
Finally, the third issue examined is how value formation for risk reduction is affected by repeated exposure to the market. It is well documented that individuals misperceive risky events in static one-shot environments. The "sharpness" of prior information about the risk has little chance to improve without sequential decisions which involve learning [see viscusi (1979)]. As noted by Hayek (1945), the market provides the opportunity for an individual to update prior misperceptions since irrelevant information has been forced out. To determine whether repeated exposure to the market significantly influences value formation, the experiment is designed such that each risk is reduced over twelve repeated trials. The first trial is the static, one-shot hypothetical reduction often used in nonmarket valuation experiments. The next ten trials are nonhypothetical market auctions for self-protection or self-insurance. The final trial is the "experienced" hypothetical risk reduction.

We find that values form rapidly in all experimental

markets. The rapid value formation indicates that learning about risk through the market does occur. The results indicate that the bias associated with the misperception of risk is greatly reduced with only one or two additional market trials. The market for risk reduction induces the process necessary for stable perceptions and values, without additional external information. 
The paper proceeds as follows: Section 2 describes the experimental design. The experimental results are outlined in Section 3, and the conclusions in section 4 .

\section{Experimental Design: self-protection, self-Insurance, and} the Psychology of Risk Reduction

The experimental design captures three fundamental issues in the theory of choice under risk: how individuals value risk given alternative reduction mechanisms, how individuals value reductions over a range of risks, and how these values are affected by repeated market trials. Consider each issue in more detail. First, we examine if the risk reduction mechanisms matter. Psychologists have discovered that choice and values are systematically influenced by alternative means of representing or framing an identical problem [e.g., Tversky and Kahneman (1981)]. This evidence makes it increasingly difficult to accept on faith that alternative risk reduction mechanisms do not influence individual value formation. To test whether alternative mechanisms matter, we construct an experimental market to quantify the framing of reduced risk. The experimental market was framed so that each subject would value reduced risk through one of four mechanisms: private self-protection, private selfinsurance, collective self-protection, and collective selfinsurance.

Given one can discriminate between self-protection and selfinsurance expenditures, is one reduction scheme preferred to another? current economic theory yields an ambiguous answer. 
Boyer and Dionne (1983) argue that a risk averse consumer will always prefer private self-insurance to self-protection since the former is more efficient in reducing an equivalent risk. According to Chang and Ehrlich (1985), however, self-insurance will not be preferred to self-protection since both must be equally desirable in terms of marginal contribution to expected utility. In our experimental design, the individual purchasing self-protection is guaranteed a monetary gain, while the purchaser of self-insurance is not. Self-protection reduces the probability of a loss to zero, implying a $100 \%$ chance of receiving the gain. Self-insurance, however, reduces the severity of the probable loss to zero, but does not alter the probability of receiving the monetary gain. Therefore, a riskaverse or risk-neutral individual will value self-protection more highly than self-insurance [see shogren (1988) for the proof].

In terms of private versus collective risk reduction, if the individual can always produce a given reduction at less cost privately than collectively, he will do so [see Shogren and crocker (1989b)]. The individual's preference for collective or private reduction will depend on the perceived productivity of his payment. The collective reduction may prove more efficient given scale economies since many private actions are too expensive or complicated to be economically feasible. If the individual perceives excessive free riding behavior, however, collective action will not be valued as highly as private action. It follows that large collective values exist only when the 
individual is an inefficient private self-protector, or if he is uninformed about private opportunities.

The second issue in experimental design is how individuals value reductions over a range of risk. Both psychologists and economists have observed systematic violations of the "linearity in probabilities" property of the independence axiom in expected utility theory [see Machina (1982, 1983), Covello (1984)]. Studies have found individuals oversensitive to changes in the probability of low risk events, and undersensitive to high risk events [e.g., Fischhoff et al. (1984), Viscusi and Magat (1987)] . This violation is particularly damaging since it implies nonrecovery of the von Neumann-Morgenstern expected utility function. To examine this issue, a range of lotteries was constructed to determine if and how behavior in low risk lotteries differs from behavior in high risk lotteries. We use a binary lottery to construct the risks $(\pi,-\$ L ;(1-\pi),+\$ G)$, where $\pi(0 \leq \pi \leq 1)$ is the probability of a monetary loss $\$ L$, and $(1-\pi)$ is the probability of a monetary gain \$G. In each experimental market, subjects were asked to report separate bids stating the maximum he or she would be willing to pay to reduce four levels of risk (18, 10\%, 208, 408).

The third issue in experimental design is to consider how individual values respond to repeated exposure to self-protection and self-insurance opportunities. Expenditures to reduce risk are rarely in terms of one-shot lifetime contributions. An individual's first market expenditure is often significantly 
different from his last. The first expenditure is based on prior information that is often incorrect. From a Bayesian perspective, repeated exposure to the market will allow the individual to update his perception and, therefore, his value of a reduction in risk [see Viscusi (1979)]. A market influences individual learning of value due to the learning-feedback environment of a repetitive framework. Therefore, to determine how multiple market exposure to alternative risk reduction mechanisms affects value formation, we explore the dynamics of repeated market trials compared to a static one-shot response.

The experiment began by eliciting an inexperienced hypothetical bid (UEHB) for each level of risk. The UEHB bid was not binding, did not influence take-home pay, and the lotteries were not resolved. Next, ten nonhypothetical bids were elicited in sequentially repeated trials for each risk (TI-T10). These ten bids were binding, did influence take-home pay, and the lotteries were resolved. Finally, an experienced hypothetical bid (EHB) was obtained. In all each subject reported 48 bids. Table 1 summarizes the experimental design and economic hypotheses. The actual instructions for the private selfprotection market are in the Appendix. See Shogren (1988) for a detailed description of the experimental design, and the instructions for the other experimental markets.'

\section{Experimental Results}

one hundred and twenty subjects participated in the experiment. All subjects were recruited from the undergraduate 
program at Appalachian State University. ${ }^{2}$ Five experiment sessions with six subjects each were run for each of the four asset markets. Table 2 summarizes the results for risk reductions for all four asset markets and levels of risk (lottery periods). ${ }^{3}$ The first two columns describe the four experimental asset markets and the four probabilities (risks) of a potential loss in assets. The table reports two measures of central tendency for each bid (inexperienced hypothetical bid, average nonhypothetical bid over ten trials, and experienced hypothetical bid); the estimated mean and median in dollars; and one measure of dispersion, the estimate variance. ${ }^{4}$

\subsection{Risk Valuation Is sensitive to the Risk Reduction Mechanism To examine the impact of alternative risk reduction} mechanisms we first compare the private and collective markets, and then compare the self-protection and self-insurance markets. The private risk reduction markets were organized as a vickrey sealed-bid second-price auction [Vickrey (1961)]. Each subject competes for the purchase of protection or insurance. The winner is the subject with the highest bid who pays the second highest bid for a $100 \%$ reduction in risk. Both the winner and second bid were posted as the only public information for each auction. 5 The collective risk reduction markets were organized as modified sealed-bid Smith Auctions [Smith (1980)]. The Smith Auction works as follows. Each subject provides a bid to reduce risk to zero. If the sum of the bids equals or exceeds the costs of providing a 1008 reduction in risk, then an adjusted (or 
average) bid is posted as the reigning price of protection or insurance. Acceptance by the collective of the price occurs only if all members agree. If at least one subject disagrees, then everyone is subject to a controlled draw of the lottery. If the sum of bids does not exceed costs, then a controlled draw of the lottery occurs. 6

Table 3 shows that the experienced hypothetical bid (EHB) for private risk reductions exceeded the bid for collective reductions (with one exception). Using a wilcoxon rank-sum test, we did not accept the hypothesis that the mean EHB bid for the respective private risk reduction through self-protection or self-insurance were derived from the same parental distribution as the collective reductions.

Table 3 also indicates that for the four risks the mean bids for private self-protection exceeded that for private selfinsurance. A wilcoxon rank sum test at the $95 \%$ confidence level indicates that the experienced hypothetical bids for private self-protection are significantly different from the bids for private self-insurance for all lottery periods. Respondents were willing to pay more for the private mechanism that influenced. probability than the mechanism that influenced severity. This result contradicts Boyer and Dionne's (1983) claim that private self-insurance will be preferred to self-protection. The result supports Shogren's (1988) argument that since self-protection guarantees a monetary gain, it will be preferred to selfinsurance, which only guarantees that one will not suffer a loss. 
Respondents were not willing to pay more, however, for collective mechanisms that influence probability relative to severity. A wilcoxon rank sum test indicates the experienced hypothetical bids for collective self-protection are not statistically significant from collective self-insurance for all probability periods.

In general, the mechanism, whether private or collective or whether probability or severity is reduced, is important when eliciting an economic value for a reduction in risk. Our results indicate the upper bound on value was the private, selfprotection market. The lower bound on value was the collective, self-insurance market.

The disparity in private and collective values may be due to the free-riding incentive in the collective mechanism. Individuals have an incentive to under-report willingness to pay for nonhypothetical reduced risk. ${ }^{7}$ As noted by Bennett (1987), strategic behavior between collective bidders often occurs in Smith Auctions even though collective optimality is attained. Smith (1980) found that although optimal aggregate levels of public good were provided, it was often only because the underreported values were balanced by overreported values. This balancing-out phenomena was also observed in our experimental markets. A larger proportion of subjects bid over expected consumer surplus than below. However, this proportion declined over repeated market exposure. 
The results have implications on the mechanism used to elicit individual preferences for reduced risk. Traditionally, the mechanism is a collective scheme in which an agency exogenously reduces a risk if the sum of individual payments (i.e., higher taxes, group fund) exceeds the costs of reduction [e.g., Weinstein et al. (1980), Smith and Desvousges (1987)]. A large number of risks, however, can be reduced privately through self-protection or self-insurance mechanisms. By allowing private risk reduction, our results indicate that traditional use of collective mechanisms may in fact only be a lower bound on the economic value of a reduction in risk.

\subsection{Overestimation of Low Risks Declines with Repeated Market Trials}

To determine if respondents in the experimental asset markets overemphasize small probabilities and underemphasize large probabilities, we examine the individual's risk preference in terms of a risk premium. A risk premium is the amount above expected consumer surplus the risk averse individual is willing to pay ex ante to eliminate the risk of losing $\$ L$ of their assets. If the individual overemphasizes small probabilities, then the risk premium for eliminating a $1 \%$ probability of a loss should exceed the risk premiums for a $10 \%, 20 \%$ and $40 \%$ probability. Table 4 reports the summary statistic for the four asset markets over the four levels of risk. The individual is risk averse (neutral/lover) if the ratio of bid to expected consumer surplus is greater (equal to/less) than unity. 
Respondents were initially extremely risk averse, overestimating the 1 probability of a loss in the initial inexperienced hypothetical bid. With repeated market exposure through ten nonhypothetical trials, however, the overestimation declined, especially in the self-insurance markets. Although the risk premium for the $1 \%$ probability for the self-protection experienced hypothetical bids is still larger than the other levels of risk, oversensitivity declines rapidly with market experience. ${ }^{8}$ The result supports Plott and sunder's (1982) argument that for a well-defined, mature market environment, expected utility is "not universally misleading about the nature of human capabilities and markets" (p. 692).

The observed tendency to overestimate low probability events has led to safety and health regulations that promote hazard warnings as regulatory alternatives to direct constraints on use or availability [see viscusi et al. (1986)]. The evidence indicates the overall efficacy of hazard warnings is governed not only by the risk level, but also by the information content. Our experiments indicate that the self-insurance markets disseminated information such that consumer valuations were broadly consistent with rational behavior. In both the private and collective selfinsurance markets, strict privacy with public information only about the market was sufficient to produce rational behavior. Irrelevant or nonefficient information was forced out of the market. As Hayek (1945) notes, "the most significant fact about this (market) system is the economy of knowledge with which it 
operates, or how little the individual participants need to know in order to take the right action..." [p. 35]. Consequently, risk information necessary to induce rational risk valuations may well be generated in repeated exposure to risk reduction markets that focus on severity. This observation is borne out by Brookshire et al.'s (1985) demonstration that expected utility is a capable predictor of behavior regarding earthquake hazards and self-insurance.

\subsection{Repeated Market Trials Induced Rapid Value Formation}

Coppinger et al. (1980), Coursey et al. (1987) and others have noted that a number of trial iterations are required before the respondent realizes that revealing "true" values is the dominant strategy in a vickrey or smith Auction. Therefore, it is striking how rapidly respondents adjust their initial inexperienced hypothetical bid (UEHB) in all risk reduction markets. Learning and adjustment to a dominant strategy occur during the first few nonhypothetical trials. The immediate feedback environment of the experiments induces rapid value formation.'

Table 5 illustrates that after the first three trial bids (T1 - T3) the remaining trial bids relative to the experienced hypothetical bid (EHB) revealed relatively minor adjustments in value. Using a one-tailed Wilcoxon Matched-sample test conducted at the $95 \%$ confidence level, we did not accept the hypothesis that the initial inexperienced bid (UEHB) and the EHB bid were derived from the identical parental distribution in $87.5 \%$ of the 
cases. The majority of initial UEHB bids differed significantly from the final experienced EHB. However, this difference decreased substantially with just one or two additional market exposures. In the first nonhypothetical market $T 1$, the number of cases in which $\mathrm{T} 1$ differed significantly from EHB fell to $43.8 \%$. In $\mathrm{T} 2$, this declined again to 31.38 . Finally, after only three trials in the market, in only $6.3 \%$ of the cases was the T3 bid significantly different from the final EHB bid. The bids in the remaining trials T4-T10 remained constant with minor fluctuations.

Although we find that the initial UEHB bid differed significantly from the first trial bid $T 1$, the final experienced EHB bid did not differ from the first few nonhypothetical trial bids. The results indicate that after the initial UEHB bid only one or two nonhypothetical trials were needed to induce rapid value formation. Consequently, misperception of risk may be a potentially damaging bias only if no learning or second-chance bid adjustment is allowed to compensate for incorrect prior information.

Traditional fears of risk misperception have originated from the static framework used in examining individual behavior under risk [see, for example, Lattimore et al. (1988)]. ${ }^{10}$ our evidence suggests that the static framework does not capture the individual's value formation process, which requires additional trial periods of market feedback or new information. sequential decisions involving learning (e.g., Viscusi (1979) and Viscusi 
and Magat (1987)] are more appropriate for examining the importance of feedback and value formation in determining accurate measures of value [also see coursey and schulze (1986)]

\section{Conclusions}

Four alternative risk reduction mechanisms were considered in experimental markets to determine how individuals respond to and value reduced risk. Our results indicate private selfprotection provides an upper bound on value, while collective self-insurance provides the lower bound. The significant differences in value estimates by the four risk reduction mechanisms indicate the current focus on collective selfprotection captures only one of four possible values of risk reduction. Future attempts to estimate the value of reduced risk should consider the other three mechanisms to reveal value. By doing so a more comprehensive view of value will be obtained.

In addition, the four reduction mechanisms with immediate market information feedback induced rapid learning and decreased misperception of risk. Usually value formation was complete after one or two additional market trials. Note, however, the robustness of these results declined during the $1 \%$ lottery period. The addition of repeated trials, however, still induced value formation to a degree closer to that predicted by expected utility theory, especially in the self-insurance markets that focused on the reduction of severity. 


\section{Footnotes}

1. The experimental design follows that of schulze et al. (1986). Schulze et al., however, only consider one of the four markets described in this paper, private self-insurance. 2. Bennett (1987) found student responses statistically insignificant from respondents representative of the general population. This suggests experimentation may be "satisfactorily performed using student groups" (p. 367). 3. The experimental parameters were consistent across asset markets and lottery periods: initial asset endowment $M=\$ 10$; monetary loss in assets $\mathrm{L}=\$ 4 ;$ and monetary gain in assets $G=$ \$1. The collective costs for self-protection and self-insurance for the respective lottery periods above equaled the sum of expected consumer surplus $c=\$ 0.3(18 \mathrm{risk}), \$ 3(108 \mathrm{risk}), \$ 6$ (20\% risk), and $\$ 12(40 \% \mathrm{risk})$. The expected consumer's surplus equals the difference between the maximum lottery income ( $M+G)$ and the expected value of the lottery $\mathrm{EV}=\mathrm{P}(\mathrm{M}-\mathrm{L})+(1-\mathrm{P})(\mathrm{M}+$ G). For example, in the $20 \%$ lottery period, $E S=(10+1)-$ $.2(10-4)-.8(10+1)=\$ 1$. 4. Forsythe et al. (1982) note the frustrating "open problems that are being encountered in almost all experimental work where the costs of conducting experiments places a significant constraint on the number of observations" (p. 549). Given the sample size of $n=30$ for each asset market, one must heed Forsythe et al.'s warning that "statistical tests we report should be 
regarded more as measures than classical hypothesis tests" (p. 549).

5. Since Vickrey's (1961) initial utilization, the second-price auction mechanism has well-known demand revealing properties. The subject's dominant strategy is to reveal full preferences since the subject does not pay what he or she bid. Incentives for false bids do not exist. As coursey (1987) notes, the use of the Vickrey auction allows one to assume "that behavior in situations where values are being measured will be well approximated in situations where values are induced" [p. 293]. As such, the Vickrey auction completes the identification of Smith's (1982) triad of components specific to behavior: the environment (including values), the instrument or institution, and the actual observed behavior.

6. Communication among subjects is forbidden. The experimenter sets the costs $\$ C$ of $100 \%$ risk reduction equal to the sum of expected consumer surplus given the lottery period. Costs were not posted. The Smith Auction process was modified in three ways: (i) given a $100 \%$ risk reduction, subjects were not asked to provide bids for the quantity of collective good, (ii) no rebate rule was used, and (iii) there was no stopping rule after unanimous agreement; all 12 auctions were completed. 7. Note this incentive to understate willingness to pay is due to the nonhypothetical nature of the ten market trials. The subject's take-home pay was determined by his or her bids. In hypothetical markets where subjects do not actually pay for 
protection or insurance, then one might find results to support the old notion that individuals overstate their bids to bias the results toward certain provision of the public good. Since the individuals do not actually pay anything, then they have an incentive to overstate their preferences. Our results indicate that given repeated nonhypothetical market exposure, there was no overstating on the final experienced hypothetical bid (EHB). The EHB bid behaved similarly to the nonhypothetical bids (T1-T10). 8. Kunreuther et al. (1985) noted the substantial empirical evidence suggesting individuals are unwilling to insure or protect themselves against low probability/high severity events. In light of this finding, our results support a notion of preference reversal in that the willingness to pay a risk premium was the highest for the low probability lottery. Yet apparently this behavior is reversed in real-world risks such as seat belts and federally subsidized flood insurance [Kunreuther et al. (1985)] .

9. The speed of convergence could be dependent on the parameters of the experimental market. However, in other experimental contexts, a parameter such as group size has had mixed results in altering the speed of convergence. For example, Smith (1982) notes that allocations and prices converge to predicted competitive equilibrium outcomes within three to four trading periods or less. This result holds with as few as six to eight buyers and as few as two sellers [Propositions 4 and 5, p. 945]. 10. Lattimore et al. (1988) found that the expected utility 
model did not fare well in comparison to the probabilitytransform model of Yaari (1987). However, their experiment was designed as a one-shot decision problem. The subjects did not have an opportunity to learn from repeated action in the market. Consequently, there was no opportunity to update incorrect prior perceptions of risk. 
Bennett, J. (1987). Strategic Behavior. Journal of Public Economics 32: 355-368.

Boyer, M. and Dionne, G. (1983). Variations in the Probability and Magnitude of Loss: Their Impacts on Risk. Canadian Journal of Economics 16: 409-19.

Brookshire, D., Thayer, M., Tschirhart, J. and Schuize, W. (1985). A Test of the Expected Utility Model: Evidence from Earthquake Risks. Journal of Political Economy 93: 369-389.

Centner, T. and Wetzstein, M. (1987). Reducing Moral Hazard Associated with Implied Warranties of Animal Health. American Journal of Agricultural Economics 69: 143-150.

Chang, Y-M. and Ehrlich, I. (1985). Insurance, Protection from Risk, and Risk-Bearing. Canadian Journal of Economics 18: $574-86$.

Coppinger, V., Smith, V.L., and Titus, J. (1980). Incentives and Behavior in English, Dutch and Sealed-Bid Auctions." Economic Inquiry 18: 1-22.

Coursey, D. (1987). Markets and the Measurement of Value. public Choice 55: 291-97.

Coursey, D., Hovis, J., and Schulze, W. (1987). The Disparity between Willingness to Accept and willingness to Pay Measures of Value. Quarterly Journal of Economics 102: 67990.

Coursey, D. and Schulze, W. (1986). The Application of Laboratory Experimental Economics to the contingent Valuation of Public Goods. Public Choice 49: 47-68.

Covello, V. (1984). Actual and Perceived Risk: A Review of the Literature. Technological Risk Assessment (P. Ricci, L. Sagen, and C. Whipple, eds.). The Hague: Martinus Nijhoff Publishers, 225-46.

Ehrlich, I. and Becker, G. (1972). Market Insurance, SelfProtection, and Self-Insurance. Journal of Political Economy 80: 623-48.

Fischhoff, B. et al. (1984). Acceptable Risk. Cambridge: Cambridge University Press. 
Forsythe, R., Palfrey, T. and Plott, C. (1982). Asset Valuation in an Experimental Market. Econometrica 50: 537-567.

Hayek, F. (1945). The Use of Knowledge in Society. American Economic Review 35: 519-530.

Hiebert, L. (1983). Self-Insurance, Self-Protection, and the Theory of the Competitive Firm. Southern Economic Journal 50: $160-168$.

Kunreuther, H., Sanderson, W. , and Vetschera, R. (1985). A Behavioral Model of the Adoption of Protective Activities. Journal of Economic Behavior and Organization 6: 1-15.

Lattimore, P., Whittle, A. and Baker, J. (1988). An Empirical Assessment of Alternative Models of Risky Decision Making. NBER Working paper no. 2717.

Machina, M. (1982). "Expected Utility" Analysis without the Independence Axiom. Econometrica 50: 277-323.

Machina, M. (1983). The Economic Theory of Individual Behavior Toward Risk: Theory, Evidence, and New Directions.

Stanford University: Technical Report No. 433.

Plott, C. and Sunder, S. (1982). Efficiency of Experimental Securities Markets with Insider Information: An Application of Rational Expectations Models. Journal of Political Economy 90: 663-98.

Schulze, W., McClelland, G., and Coursey, D. (1986). Valuing Risk: A Comparison of Expected Utility with Models from Cognitive Psychology. Unpublished Manuscript.

Shogren, J. (1988). Valuing Risk in Experimental Markets: SelfProtection, Self-Insurance, and Collective Action. Final Draft Report, U.S. Environmental Protection Agency.

Shogren, J. and Crocker, T. (1989a). Risk, Self-Protection, and Ex Ante Economic Value. Estimating and Valuing Morbidity in a Policy Context. Research Triangle Institute: AERE Workshop Proceedings.

Shogren, J. and Crocker, T. (1989b). Adaptation and the option Value of Uncertain Environmental Resources. Mimeo.

Smith, V.K. and Desvousges, W. (1987). An Empirical Analysis of the Economic Value of Risk Changes. Journal of Political Economy 95: 89-114. 
Smith, V.L. (1980). Experiments with a Decentralized Mechanism for Public Good Decisions. American Economic Review 70: 584-90.

Smith, V.L. (1982). Microeconomic Systems as an Experimental Science. American Economic Review 72: 923-55.

Tversky, A. and Kahneman, D. (1981). The Framing of Decisions and the Psychology of choice. Science 211: 453-458.

Vickrey, W. (1961). Counterspeculation, Auctions and Competitive Sealed Tenders. Journal of Finance 16: 8-37.

Viscusi, W.K. (1979). Insurance and Individual Incentives in Adaptive Contexts. Econometrica 47: 1195-1207.

Viscusi, W.X. Magat, W., and Huber, J. (1986). Information Regulation of Consumer Health Risks: An Empirical Evaluation of Hazard Warnings. Rand Journal of Economics 17: $351-365$.

Viscusi, W.K. and Magat, w. (1987). Learning about Risk: Consumer and Worker Responses to Hazard Information. Cambridge: Harvard University Press.

Weinstein, M., Shepard, D. and Pliskin, J. (1980). The Economic Value of Changing Mortality Probabilities: A DecisionTheoretic Approach. Quarterly Journal of Economics 94 : $373-96$.

Yaari, M. (1987). The Dual Theory of Choice Under Risk. Econometrica 55: 95-115. 
TABLE 1

Summary of Experimental Design

A. Alternative Risk Reduction Mechanisms:

Private Self-Protection

Private Self-Insurance

Collective Self-protection

collective Self-Insurance
Does the Risk Reduction

Mechanism Matter?

Are individuals indifferent

to Private versus Collective

Mechanisms?

Are individuals indifferent to mechanisms that influence probability versus severity?
B. Valuation over a Range

of Risks:

$L=[\pi,-\$ L ;(1-\pi),+\$ G]$

where

$\pi=1 \%, 10 \%, 20 \%$, or $40 \%$

probability of a loss $(-\$ L)$
Do individuals overestimate changes in the probability of low risk events?

If so, how does overestimation respond to the alternative risk reduction mechanisms over repeated trials?
C. Valuation over Repeated Market Trials:

Inexperienced Hypothetical Bid (UEHB)

Repeated Nonhypothetical Bids (T1-T10)

Experienced Hypothetical Bid (EHB)
Does repeated exposure to the market induce rapid value formation for risk reductions? Are initial one-shot bids significantly different from final experienced bids? 
TABLE 2

Summary Statistic of Experimental Asset Markets

for Risk Reduction

\begin{tabular}{|c|c|c|c|c|c|c|c|c|c|c|}
\hline \multirow{2}{*}{$\begin{array}{l}\text { Asset } \\
\text { Market }\end{array}$} & \multicolumn{2}{|c|}{ obability } & \multicolumn{2}{|c|}{$\begin{array}{l}\text { Inexperienced } \\
\text { Hypothetical } \\
\text { Bid (UEHB) }\end{array}$} & \multicolumn{3}{|c|}{$\begin{array}{l}\text { Average } \\
\text { Nonhypothetical } \\
\text { Bid (ANB) }\end{array}$} & \multicolumn{3}{|c|}{$\begin{array}{c}\text { Experienced } \\
\text { Hypothetical } \\
\text { Bid(EHB) }\end{array}$} \\
\hline & A Loss & Mean & Median & Variance & Mean & Median & Variance & Mean & Median & Variance \\
\hline $\begin{array}{l}\text { 1.Self- } \\
\text { Protection } \\
\text { (Private) }\end{array}$ & $\begin{array}{r}18 \\
108 \\
208 \\
408\end{array}$ & $\begin{array}{l}2.73 \\
2.87 \\
3.35 \\
4.62\end{array}$ & $\begin{array}{l}1.50 \\
3.00 \\
3.08 \\
4.00\end{array}$ & $\begin{array}{r}11.72 \\
5.42 \\
5.40 \\
7.45\end{array}$ & $\begin{array}{l}0.78 \\
1.09 \\
2.93 \\
3.93\end{array}$ & $\begin{array}{l}0.38 \\
2.98 \\
3.36 \\
3.70\end{array}$ & $\begin{array}{l}0.94 \\
1.42 \\
1.49 \\
2.66\end{array}$ & & $\begin{array}{l}0.35 \\
1.38 \\
3.50 \\
4.00\end{array}$ & $\begin{array}{l}2.08 \\
4.19 \\
3.80 \\
4.57\end{array}$ \\
\hline $\begin{array}{l}\text { 2. Self- } \\
\text { Insurance } \\
\text { (Private) }\end{array}$ & $\begin{array}{r}18 \\
108 \\
208 \\
408\end{array}$ & $\begin{array}{l}1.85 \\
2.93 \\
3.93 \\
4.91\end{array}$ & $\begin{array}{l}0.50 \\
2.28 \\
4.00 \\
5.00\end{array}$ & $\begin{array}{r}10.35 \\
6.23 \\
5.26 \\
5.32\end{array}$ & $\begin{array}{l}0.09 \\
1.09 \\
2.56 \\
3.35\end{array}$ & $\begin{array}{l}0.07 \\
0.79 \\
2.16 \\
3.31\end{array}$ & $\begin{array}{l}0.02 \\
1.10 \\
2.69 \\
1.81\end{array}$ & & $\begin{array}{l}0.03 \\
0.86 \\
2.25 \\
3.58\end{array}$ & $\begin{array}{l}2.01 \\
0.92 \\
2.59 \\
1.87\end{array}$ \\
\hline $\begin{array}{l}\text { 3. Self- } \\
\text { Protection } \\
\text { (Collect- } \\
\text { ive) }\end{array}$ & $\begin{array}{r}18 \\
108 \\
208 \\
408\end{array}$ & $\begin{array}{l}2.79 \\
2.74 \\
2.77 \\
3.04\end{array}$ & $\begin{array}{l}1.00 \\
2.00 \\
3.00 \\
3.00\end{array}$ & $\begin{array}{r}12.37 \\
6.57 \\
3.04 \\
2.39\end{array}$ & $\begin{array}{l}0.84 \\
0.80 \\
1.27 \\
2.13\end{array}$ & $\begin{array}{l}0.06 \\
0.54 \\
1.02 \\
2.02\end{array}$ & $\begin{array}{l}3.30 \\
0.60 \\
0.89 \\
1.46\end{array}$ & $\begin{array}{l}0.78 \\
0.75 \\
1.00 \\
2.09\end{array}$ & $\begin{array}{l}0.06 \\
0.48 \\
0.90 \\
2.00\end{array}$ & $\begin{array}{l}3.97 \\
0.89 \\
0.32 \\
1.34\end{array}$ \\
\hline $\begin{array}{l}\text { 4. Self- } \\
\text { Insurance } \\
\text { (Collect- } \\
\text { ive) }\end{array}$ & $\begin{array}{l}18 \\
108 \\
208 \\
408\end{array}$ & $\begin{array}{l}0.97 \\
1.25 \\
1.81 \\
2.55\end{array}$ & $\begin{array}{l}0.50 \\
1.00 \\
2.00 \\
2.50\end{array}$ & $\begin{array}{l}2.82 \\
1.03 \\
0.91 \\
2.22\end{array}$ & $\begin{array}{l}0.77 \\
0.70 \\
1.26 \\
1.95\end{array}$ & $\begin{array}{l}0.06 \\
0.50 \\
0.88 \\
1.41\end{array}$ & $\begin{array}{l}7.09 \\
0.77 \\
2.23 \\
3.19\end{array}$ & $\begin{array}{l}0.78 \\
0.43 \\
1.11 \\
1.73\end{array}$ & $\begin{array}{l}0.02 \\
0.38 \\
1.00 \\
1.21\end{array}$ & $\begin{array}{l}0.03 \\
0.20 \\
1.21 \\
2.14\end{array}$ \\
\hline
\end{tabular}

${ }^{a} n=30$ for each asset market: five experiments with six subjects each.

NOTE: We do not accept the null hypothesis that the population mean is zero at the .01 level using a one-tailed test for all UEHB, ANB, and EHB bids across asset markets and lottery periods. 
TABLE 3

Wilcoxon Rank-Sum Tests Between Risk

Reduction Mechanisms

Experienced Nonhypothetical Bid (EHB)

\begin{tabular}{lrr}
\hline Market & Test \\
Statistic
\end{tabular}

A. Private vs. Collective

Self-Protection

Self-Insurance

B. Self-Protection vs. Self-Insurance Private

Collective
18

108
208
408

18

108

208

$40 \%$

18

108

208

408

18
$1.936 *$

$3.374 *$
$5.073 *$
$4.883 *$

0.576

$3.882 *$

4. $142 *$

$3.996 *$

\begin{tabular}{rrr} 
Collective & \multicolumn{1}{c}{18} & 1.702 \\
& 108 & 1.289 \\
& 208 & 0.059 \\
& 408 & 1.718
\end{tabular}

* - significant at $95 \%$ level that bids were not derived from the same parental distribution. 
TABLE 4

Summary statistic of Risk Premiums

\begin{tabular}{|c|c|c|c|c|}
\hline Risk & $\begin{array}{l}\text { Asset } \\
\text { Market }\end{array}$ & $\begin{array}{l}\text { Inexperienced } \\
\text { Hypothetical Bid } \\
\text { Mean/E[CS }]^{\mathrm{a}}\end{array}$ & $\begin{array}{c}\text { Average } \\
\text { Nonhypothetical Bid } \\
\text { Mean/E[CS] }\end{array}$ & $\begin{array}{r}\text { Experienced } \\
\text { Hypothetical } \\
\text { Mean/E[CS] }\end{array}$ \\
\hline 18 & $\begin{array}{l}S P^{b} \\
S I \\
\operatorname{CSP} \\
C S I\end{array}$ & $\begin{array}{l}54.60^{c} \\
37.00 \\
55.80 \\
19.40\end{array}$ & $\begin{array}{r}15.60 \\
1.79 \\
16.84 \\
15.40\end{array}$ & $\begin{array}{r}16.20 \\
1.41 \\
15.52 \\
1.40\end{array}$ \\
\hline 108 & $\begin{array}{l}\text { SP } \\
\text { SI } \\
\operatorname{CSP} \\
\operatorname{CSI}\end{array}$ & $\begin{array}{l}5.74 \\
5.80 \\
5.48 \\
2.50\end{array}$ & $\begin{array}{l}3.48 \\
2.18 \\
1.60 \\
1.40\end{array}$ & $\begin{array}{l}4.04 \\
2.26 \\
1.51 \\
0.86\end{array}$ \\
\hline 208 & $\begin{array}{l}\text { SP } \\
\text { SI } \\
\operatorname{CSP} \\
\operatorname{CSI}\end{array}$ & $\begin{array}{l}3.35 \\
3.93 \\
2.77 \\
1.81\end{array}$ & $\begin{array}{l}2.93 \\
2.56 \\
1.27 \\
1.26\end{array}$ & $\begin{array}{l}3.45 \\
2.44 \\
1.00 \\
1.11\end{array}$ \\
\hline 408 & $\begin{array}{r}S P \\
S I \\
\operatorname{CSP} \\
\operatorname{CSI}\end{array}$ & $\begin{array}{l}2.31 \\
2.46 \\
1.52 \\
1.28\end{array}$ & $\begin{array}{l}1.97 \\
1.73 \\
1.06 \\
0.98\end{array}$ & $\begin{array}{l}2.19 \\
1.67 \\
1.04 \\
0.87\end{array}$ \\
\hline
\end{tabular}

- - E[CS] represents expected consumer surplus $E[C S]=\$ 1, \$ .5, \$ .05$, and $\$ 2$ for probability $=20 \%, 10 \%, 1 \%$, and $40 \%$.

b SP: Private Self-Protection, SI: Private Self-Insurance CSP: Collective Self-Protection, CSI: Collective Self-Insurance

c - Mean/E[CS] > $1(=1 /<1)$ implies risk aversion (neutrality/lover). 
TABLE 5

Wilcoxon Matched-Sampled Sign Test Between the Experienced Nonhypothetical Bid (EHB) and Bids over the Repeated Market Trials

\begin{tabular}{|c|c|c|c|c|c|c|c|c|c|}
\hline \multirow{2}{*}{$\begin{array}{l}\text { Asset } \\
\text { Market }\end{array}$} & \multirow[b]{2}{*}{ Risk (f) } & \multicolumn{2}{|l|}{ UEHB } & \multicolumn{2}{|c|}{$\mathrm{T} 1$} & \multicolumn{2}{|c|}{$\mathrm{T} 2$} & \multicolumn{2}{|c|}{$\mathrm{T} 3$} \\
\hline & & $z^{a}$ & $p^{b}$ & $\mathbf{Z}$ & $\underline{P}$ & $\mathrm{Z}$ & $\underline{\mathbf{P}}$ & $\mathrm{Z}$ & $\mathbf{P}$ \\
\hline $\begin{array}{l}\text { Private Self- } \\
\text { Protection }\end{array}$ & $\begin{array}{r}1 \\
10 \\
20 \\
40\end{array}$ & $\begin{array}{l}-3.111 * \\
-2.287 \star \\
-0.900 \\
-0.659\end{array}$ & $\begin{array}{r}.00 \\
.02 \\
.37 \\
.51\end{array}$ & $\begin{array}{l}-0.015 \\
-1.251 \\
-2.676 \star \\
-2.327 \star\end{array}$ & $\begin{array}{r}.99 \\
.21 \\
.01 \\
.02\end{array}$ & $\begin{array}{c}-- \\
-2.490 * \\
-2.798 *\end{array}$ & $\begin{array}{l}-- \\
-- \\
.01 \\
.01\end{array}$ & $\begin{array}{c}-- \\
-1.893 \\
-3.429 *\end{array}$ & $\begin{array}{l}-- \\
-- \\
.07 \\
.00^{c}\end{array}$ \\
\hline $\begin{array}{l}\text { Private Self- } \\
\text { Insurance }\end{array}$ & $\begin{array}{l}1 \\
10 \\
20 \\
40\end{array}$ & $\begin{array}{l}-3.772 * \\
-3.945 * \\
-3.730 \star \\
-3.038 \star\end{array}$ & $\begin{array}{r}.00 \\
.00 \\
.00 \\
.00\end{array}$ & $\begin{array}{l}-1.338 \\
-0.152 \\
-1.764 \\
-2.198 *\end{array}$ & $\begin{array}{r}.18 \\
.88 \\
.08 \\
.03\end{array}$ & $\begin{array}{c}-- \\
-- \\
-- \\
-1.686\end{array}$ & $\begin{array}{l}-- \\
-- \\
-09\end{array}$ & $\begin{array}{l}-- \\
-- \\
-- \\
--\end{array}$ & $\begin{array}{l}-- \\
-- \\
-- \\
--\end{array}$ \\
\hline $\begin{array}{l}\text { Collective } \\
\text { Self-Protection }\end{array}$ & $\begin{array}{l}1 \\
10 \\
20 \\
40\end{array}$ & $\begin{array}{l}-4.076 * \\
-4.444 \star \\
-4.360 * \\
-2.550 \star\end{array}$ & $\begin{array}{r}.00 \\
.00 \\
.00 \\
.01\end{array}$ & $\begin{array}{l}-1.399 \\
-2.391 * \\
-3.495 * \\
-1.069\end{array}$ & $\begin{array}{r}.16 \\
.02 \\
.00 \\
.29\end{array}$ & $\begin{array}{c}--\overline{1} \\
-2.277 \star \\
-0.699 \\
--\end{array}$ & $\begin{array}{r}-- \\
.02 \\
.48 \\
--\end{array}$ & $\begin{array}{c}-- \\
-0.744 \\
-- \\
--\end{array}$ & $\begin{array}{c}-\overline{-} \\
.46 \\
-- \\
--\end{array}$ \\
\hline $\begin{array}{l}\text { Collective } \\
\text { Self-Insurance }\end{array}$ & $\begin{array}{r}1 \\
10 \\
20 \\
40\end{array}$ & $\begin{array}{l}-4.373 \star \\
-4.474 \star \\
-3.712 \star \\
-3.014 \star\end{array}$ & $\begin{array}{r}.00 \\
.00 \\
.00 \\
.00\end{array}$ & $\begin{array}{l}-3.736 * \\
-2.607 \star \\
-1.812 \\
-1.457\end{array}$ & $\begin{array}{r}.00 \\
.01 \\
.07 \\
.15\end{array}$ & $\begin{array}{c}-2.877 * \\
-2.184 * \\
-- \\
--\end{array}$ & $\begin{array}{r}.00 \\
.03 \\
-- \\
--\end{array}$ & $\begin{array}{c}-1.448 \\
-0.209 \\
-- \\
--\end{array}$ & $\begin{array}{r}.15 \\
.83 \\
-- \\
--\end{array}$ \\
\hline
\end{tabular}

- Test statistic

- Observed Significance Level

c - At Trial T6 there was no significant difference at the $95 \%$ level $[\mathrm{Z}=-1.802$ and $\mathrm{P}=.07]$

* - Significant statistical difference at $95 \%$ level. 
APPENDIX

Instructions

General

You are about to participate in an experiment about decision making under risk and uncertainty. The purpose of the experiment is to gain insight into certain features of economic processes. If you follow the instructions carefully you can earn money. You will be paid in cash at the end of the experiment.

Specific Instructions

You will be asked to make several decisions. Each decision will involve stating your maximum willingness to pay bid to eliminate a potential risk. You are not to reveal your bid to any other participant. Note that any communication between bidders during a trial will result in an automatic loss of $\$ 4$.

over the course of the experiment, you will be asked to bid your maximum willingness to pay to prevent a loss of $\$ 4$ for a series of different probability periods $(40 \%, 20 \%, 10 \%$, and $1 \%)$. For example, given an initial starting income of $\$ 10$, if there is a $60 \%$ chance that you will gain $\$ 1$, and a $40 \%$ chance that you will lose $\$ 4$, what is the maximum you would be willing to pay to guarantee a $100 \%$ chance of winning $\$ 1$ and a $0 \%$ chance of losing $\$ 4 ?$ - There will be ten bidding trials in each probability period. Note that for each trial the starting income will always be $\$ 10$. Your gains or losses do not carry over to the next trial or probability period.

Each participant is competing to purchase the right to 
protect him/herself from a certain probability of a $\$ 4$ loss. The participant with the highest willingness to pay bid wins this right of protection and will be guaranteed a $0 \%$ chance of a $\$ 4$ loss and a $100 \%$ chance of a $\$ 1$ gain. The highest bidder must in all cases pay the bid of the second highest bidder. All other participants are then subject to a random draw to determine if a loss or gain occurs. Note that in the event that there is a tie for the highest bid, those participants will be asked to rebid.

The actual experiment will proceed as follows:

Step 1: At the beginning of the experiment you will state a separate hypothetical bid for reducing each of the four probabilities of a loss to zero.

Step 2: The experimenter selects a probability period.

Step 3: Ten bidding trials will be run for the selected probability period.

Step 4: At the beginning of each bidding trial for a given probability period, you will state a bid by writing it on the recording card. Note that your initial income remains at $\$ 10$ for each trial regardless of your winnings or losses in the trial periods before.

Step 5: After the recording card has been collected from each participant, the experimenter will display the winner (the highest bidder) and the price of protection on the blackboard. The winner must pay the displayed price of protection.

Step 6: The experimenter will then draw one chip from the urn. A white chip results in a $\$ 1$ gain for everyone, a red 
protect him/herself from a certain probability of a $\$ 4$ loss. The participant with the highest willingness to pay bid wins this right of protection and will be guaranteed a $0 \%$ chance of a $\$ 4$ loss and a $100 \%$ chance of a $\$ 1$ gain. The highest bidder must in all cases pay the bid of the second highest bidder. All other participants are then subject to a random draw to determine if a loss or gain occurs. Note that in the event that there is a tie for the highest bid, those participants will be asked to rebid.

The actual experiment will proceed as follows:

Step 1: At the beginning of the experiment you will state a separate hypothetical bid for reducing each of the four probabilities of a loss to zero.

Step 2: The experimenter selects a probability period.

Step 3: Ten bidding trials will be run for the selected probability period.

Step 4: At the beginning of each bidding trial for a given probability period, you will state a bid by writing it on the recording card. Note that your initial income remains at $\$ 10$ for each trial regardless of your winnings or losses in the trial periods before.

Step 5: After the recording card has been collected from each participant, the experimenter will display the winner (the highest bidder) and the price of protection on the blackboard. The winner must pay the displayed price of protection.

Step 6: The experimenter will then draw one chip from the urn. A white chip results in a $\$ 1$ gain for everyone, a red 
chip results in a $\$ 4$ loss for everyone (except the highest bidder).

Step 7: After ten trial periods, a final hypothetical bid will be elicited for the probability period.

Step 8: The process will repeat until all four probability periods have been examined. Your take home income will consist of your initial income plus or minus your gains, losses, and purchases of protection.

Are there any questions? 